University of Nebraska - Lincoln

DigitalCommons@University of Nebraska - Lincoln

Technical note: Whole-pen assessments of nutrient excretion and digestibility from dairy replacement heifers housed in sandbedded freestalls

\author{
W. K. Coblentz \\ USDA-ARS, wayne.coblentz@ars.usda.gov \\ P. C. Hoffman \\ University of Wisconsin \\ N. M. Esser \\ University of Wisconsin \\ M. G. Bertram \\ University of Wisconsin
}

Follow this and additional works at: https://digitalcommons.unl.edu/usdaarsfacpub

Coblentz, W. K.; Hoffman, P. C.; Esser, N. M.; and Bertram, M. G., "Technical note: Whole-pen assessments of nutrient excretion and digestibility from dairy replacement heifers housed in sand-bedded freestalls" (2013). Publications from USDA-ARS / UNL Faculty. 1237.

https://digitalcommons.unl.edu/usdaarsfacpub/1237

This Article is brought to you for free and open access by the U.S. Department of Agriculture: Agricultural Research Service, Lincoln, Nebraska at DigitalCommons@University of Nebraska - Lincoln. It has been accepted for inclusion in Publications from USDA-ARS / UNL Faculty by an authorized administrator of DigitalCommons@University of Nebraska - Lincoln. 


\title{
Technical note: Whole-pen assessments of nutrient excretion and digestibility from dairy replacement heifers housed in sand-bedded freestalls ${ }^{1}$
}

\author{
W. K. Coblentz, ${ }^{* 2}$ P. C. Hoffman, $\uparrow$ N. M. Esser, \\ *US Dairy Forage Research Center, USDA-ARS, Marshfield, WI 54449; † Department of Dairy Science, University of \\ Wisconsin, Madison 53706; \$University of Wisconsin Marshfield Agricultural Research Station, Marshfield 54449; and \\ $\S$ University of Wisconsin Arlington Agricultural Research Station, Arlington 53911
}

\begin{abstract}
Our objectives were to describe and test refined procedures for quantifying excreta produced from whole pens of dairy heifers. Previous research efforts attempting to make whole-pen measurements of excreta output have been complicated by the use of organic bedding, which requires cumbersome analytical techniques to quantify excreta apart from the bedding. Research pens equipped with sand-bedded freestalls offer a unique opportunity for refinement of whole-pen fecal collection methods, primarily because sand-bedded freestall systems contain no organic bedding; therefore, concentrations of ash within the manure, sand, and feces can be used to correct for contamination of manure by sand bedding. This study was conducted on a subset of heifers from a larger production-scale feeding trial evaluating ensiled eastern gamagrass [Tripsacum dactyloides (L.) L.] haylage (EGG) that was incorporated into a corn silage/alfalfa haylage-based blended diet at rates of $0,9.1,18.3$, or $27.4 \%$ of total DM. The diet without EGG also was offered on a limitfed basis. Eighty Holstein dairy heifers were blocked (heavy weight, $424 \pm 15.9 \mathrm{~kg}$; light weight, $324 \pm 22.4$ $\mathrm{kg}$ ) and then assigned to 10 individual pens containing 8 heifers/pen. One pen per block was assigned to each
\end{abstract}

of the 5 research diets, and whole-pen fecal collections were conducted twice for each pen. Grab fecal samples also were gathered from individual heifers within each pen, and subsequent analysis of these whole-pen composites allowed reasonable estimates of OM and NDF excreta output. Under the conditions of our experimental design, pooled SEM for the excreta DM, OM, NDF, and NDF (ash corrected) output were 0.113, 0.085, 0.093 , and $0.075 \mathrm{~kg} \cdot$ heifer $^{-1} \cdot \mathrm{d}^{-1}$, respectively. For DM excretion, this represented about one-third of the SEM reported for previous whole-pen collections from bedded-pack housing systems. Subsequent calculations of apparent DM and OM digestibilities indicated that the technique was sensitive, and linear trends $(P \leq 0.027)$ associated with the inclusion rates of EGG within the diet were detected. This technique allows estimation of apparent diet digestibilities on multiple animals simultaneously, thereby mitigating the need for isolating individual animals to obtain digestibility coefficients. The approach appears viable but requires hand labor for collections of multiple pens and thorough mixing of large volumes of manure as well as analytical corrections for sand ingested by lounging heifers.

Key words: ash, dairy heifers, excreta, sand, whole-pen collections

(C) 2013 American Society of Animal Science. All rights reserved.

J. Anim. Sci. 2013.91:4841-4848

This article is a U.S. government work, and is not subject to copyright in the United States. doi:10.2527/jas2012-6168

\section{INTRODUCTION}

Several feeding studies (Hoffman et al., 2007; Kruse et al., 2010; Bjelland et al., 2011) included whole-

\footnotetext{
${ }^{1}$ Mention of trade names or commercial products in this article is solely for the purpose of providing specific information, and does not imply either recommendation or endorsement by the U.S. Department of Agriculture.

${ }^{2}$ Corresponding author: wayne.coblentz@ars.usda.gov

Received December 10, 2012.

Accepted July 3, 2013.
}

pen collections designed to determine excretions of nutrients on a whole-pen basis rather than by traditional individual-animal assessments (Cochran and Galyean, 1994). The recovery and subsequent analysis of excreta on a whole-pen basis has been complicated by use of organic bedding materials. Therefore, soiled bedding after the collection period contains organic components from both the bedding (often wooden shavings) and excreta (urine and feces). Generally, these raw manure components must be separated quantitatively by weigh- 
ing and analyzing the organic bedding materials before the collection period. Subsequently, excreta needs to be quantified by differences in DM weights and/or nutrient loads before (bedding alone) and after a 48-h collection period (bedding plus excreta; Hoffman et al., 2007). This approach also requires a dedicated collection pen, which is potentially disruptive to routine day-to-day heifer behaviors. Sand-bedded freestalls may offer an opportunity for improvement and refinement of whole-pen methods of excreta collection because sand is inorganic and entirely recovered as ash after combustion. On this basis, any contamination of the alley manure by sand should be correctable using ash as an internal marker. Our objectives for this project were to assess the efficacy of procedural refinements to whole-pen collection methods in conjunction with a large-scale production trial evaluating multiple inclusion levels of eastern gamagrass [Tripsacum dactyloides (L.) L.] haylage (EGG) within the diets of replacement dairy heifers (Coblentz et al., 2012).

\section{MATERIALS AND METHODS}

All animal handling procedures for this experiment were approved by the Research Animal Resources Committee of the University of Wisconsin-Madison (protocol number A01458).

\section{Animals, Housing, and Diets}

This project was conducted on a subset of 80 heifers that were included in a larger evaluation of EGG as high-NDF forage with potential to reduce the caloric density and DMI of corn silage/alfalfa haylage-based diets for replacement dairy heifers in Wisconsin. As such, detailed descriptions of all diets, feeding procedures, diet/ort sampling, housing, and routine animal-handling procedures have been detailed previously (Coblentz et al., 2012). Holstein heifers were sorted (40 heifers/ block) on the basis of initial BW (heavy weight, $424 \pm$ $15.9 \mathrm{~kg}$; light weight, $324 \pm 22.4 \mathrm{~kg}$ ), stratified by BW within block, and assigned in groups of 8 heifers/pen to 1 of 10 identical research pens ( 5 pens/block). For each block, heifers within each of the 5 research pens were assigned to 1 of 5 diets that included a negative control diet formulated as a 47:53 blend of alfalfa haylage and corn silage (EGG0) that exceeded energy requirements for heifers in these weight groups (NRC, 2001). Other diets were constructed with serial substitutions of EGG, primarily for corn silage, thereby creating diets comprised of $9.1,18.3$, or $27.4 \%$ EGG on a DM basis (EGG9, EGG18, or EGG27, respectively). An additional positive control diet (LF) was formulated exactly as EGG0 but was offered on a limit-fed basis at $85 \%$ of the daily intake of EGG0 (Kruse et al., 2010).

\section{Whole-Pen Collections}

Light- and heavy-weight blocks (5 research pens each) were located within different but identically configured quadrants of the barn. Whole-pen collections for the 5 pens within each block were conducted simultaneously; at approximately $0830 \mathrm{~h}$ (immediately before feeding), heifers were removed from their assigned pens briefly, and each pen was thoroughly cleaned with a small skid-steer loader. Although alleys were not washed with water, any small accumulations of feces and other waste missed by the alley scraper or skid steer loader, including manure pats in the freestalls, were removed manually with hand scrapers and shovels. At this time, automated alley-scraper blades were removed, and rubber matting was attached to the interior fencing separating each pen, thereby preventing cross-contamination of urine and feces between pens (Hoffman et al., 2007). After pens were thoroughly cleaned (total elapsed time was about 1 h), heifers were returned to their assigned pens. Immediately thereafter, heifers were fed their daily allocation of treatment total mixed ration (TMR). All urine, feces, and sand were then allowed to collect normally in the feeding, resting, and crossover alleys of each pen for $48 \mathrm{~h}$.

After the 48-h collection period, heifers were removed from their assigned pens, and all sand, feces, and urine collected from the alleys of each pen were transferred into a small $4.4-\mathrm{m}^{3}$ manure spreader (H\&S Manufacturing Company, Inc., Marshfield, WI) fitted with electronic load cells (Digi-Star, Fort Atkinson, WI). The contents of each spreader load were then discharged (with beater engagement) onto a flat concrete slab and mixed further with a small skid-steer loader. After mixing, 5 to 7 random locations were identified within the discharge pile, and an approximate 4-L sample was obtained from each location, including contributions from several depths within the pile. Each of the 5 to 7 samples per spreader load were transported back to the laboratory and thoroughly mixed, and a 20 -g subsample from each was placed in an aluminum weigh tin and then dried for $24 \mathrm{~h}$ at $100^{\circ} \mathrm{C}$. These determinations of DM were averaged to establish the mean DM concentration of the manure collected from each pen. After concentrations of DM were determined, the contents of each tin were combusted at $500^{\circ} \mathrm{C}$ for $6 \mathrm{~h}$ in a muffle furnace to determine the corresponding concentrations of ash. Grab samples of sand from the bedded stalls were analyzed for concentrations of DM and ash in an identical manner. Although sand is assumed to be $100 \%$ inorganic, this additional analysis was conducted for verification; across 4 evaluation dates, the sand bedding contained $98.0 \pm 0.35 \%$ ash.

Our facility is equipped with locking headgates along the drive-through feed alley; this additional animal-restraint equipment permits quick collection of fecal samples from each heifer within the pen as well as 
easy generation of a composite whole-pen fecal sample that is uncontaminated by bedding materials. After removing the excreta and sand mixture from each pen, the daily allocation of TMR was dispensed, and heifers were returned to their assigned pens. At this time, the locking headgates along the feed alley were set to the "lock" position, and the heifers were retained briefly as a fecal grab sample was obtained from each heifer. These samples were composited by pen and then analyzed in triplicate for concentrations of DM and ash. For this study, whole-pen collections were conducted twice within each block during the 15 -wk production trial; these collections occurred during wk 4 and 10 for lightweight heifers and wk 7 and 13 for heavy-weight heifers.

\section{Calculations}

Summary of Measured Inputs and Definition of Terms. The goals of these whole-pen collection procedures were to eliminate the contributions of sand and quantify the actual excreta DM produced within each pen during a 48-h collection period. To make these calculations, these input measurements and calculated intermediary variables are defined as

$$
\begin{aligned}
& \operatorname{CONCPEN}_{\text {DM }}=\text { concentration of DM within } \\
& \text { CONCFECAL }_{\text {ASH }}=\text { concentration of ash within }
\end{aligned}
$$

CONCSAND $_{\text {ASH }}=$ concentration of ash within sand bedding $(\%$ of $\mathrm{DM})$

PENWEIGHT $_{\text {WET }}=$ gross wet weight $(\mathrm{kg})$ of pen contents collected after $48 \mathrm{~h}(\mathrm{~kg})$

$$
\text { PENWEIGHT }_{\text {DM }}=\underset{\text { gross weight of DM collected }}{\text { from each pen }(\mathrm{kg})}
$$

PENWEIGHT $_{\text {ASH }}=$ gross weight of ash collected from each pen $(\mathrm{kg})$

PENWEIGHT $_{\text {SAND }}=$ gross weight of sand DM collected from each pen $(\mathrm{kg})$

$$
\begin{aligned}
\text { PENWEIGHT }_{\text {EXCRETA }}= & \text { gross weight of excreta } \\
& \begin{array}{l}
\text { DM collected from } \\
\text { each pen }(\mathrm{kg})
\end{array}
\end{aligned}
$$

Among these variables, $\mathrm{CONCPEN}_{\mathrm{DM}}$, $\mathrm{CONCPEN}_{\mathrm{ASH}}$, CONCFECAL $\mathrm{ASH}_{\mathrm{H}}$, CONCSAN$\mathrm{D}_{\mathrm{ASH}}$, and PENWEIGHT ${ }_{\mathrm{WET}}$ were measured directly whereas PENWEIGHT $_{\mathrm{DM}}$, PENWEIGHT $_{\mathrm{ASH}}$,

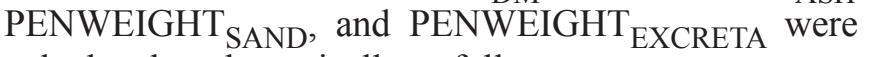
calculated mathematically as follows:

$$
\begin{aligned}
\text { PENWEIGHT }_{\mathrm{DM}}= & \mathrm{PENWEIGHT}_{\mathrm{WET}} \\
& \times \mathrm{CONCPEN}_{\mathrm{DM}}
\end{aligned}
$$

and

$$
\begin{aligned}
\text { PENWEIGHT }_{\mathrm{ASH}}= & \mathrm{PENWEIGHT}_{\mathrm{DM}} \\
& \times \text { CONCPEN }_{\mathrm{ASH}}
\end{aligned}
$$

Subsequently, PENWEIGHT ${ }_{\text {ASH }}$ can then be set equal to its individual contributions from sand and excreta by

$$
\begin{aligned}
\text { PENWEIGHT }_{\text {ASH }}= & \left(\text { PENWEIGHT }_{\text {SAND }}\right. \\
& \left.\times \text { CONCSAND }_{\text {ASH }}\right) \\
& +\left(\text { PENWEIGHT }_{\text {EXCRETA }}\right. \\
& \left.\times \text { CONCFECAL }_{\text {ASH }}\right)
\end{aligned}
$$

in which PENWEIGHT SAND $_{\text {and PENWEIGHT }}$ EXCRETA are unknown variables. As stated previously, the overall goal of these procedures is to quantify the PENWEIGHT $_{\text {EXCRETA }}(\mathrm{kg})$ obtained from each pen. To accomplish this goal, Eq. [3] can be rewritten such that there is only 1 remaining unknown variable by substituting (PENWEIGHT ${ }_{\text {DM }}-$ PENWEIGHT $_{\text {SAND }}$ ) for PENWEIGHT $_{\text {EXCRETA: }}$

$$
\begin{aligned}
\text { PENWEIGHT }_{\text {ASH }}= & \left(\text { PENWEIGHT }_{\text {SAND }}\right. \\
& \left.\times \text { CONCSAND }_{\text {ASH }}\right) \\
& +\left[\text { PENWEIGHT }_{\mathrm{DM}}\right. \\
& \left.- \text { PENWEIGHT }_{\mathrm{SAND}}\right) \\
& \left.\times \text { CONCFECAL }_{\mathrm{ASH}}\right] .
\end{aligned}
$$

After solving Eq. [4] for PENWEIGHT ${ }_{\text {SAND, }}$ PENWEIGHT $_{\text {EXCRETA }}$ can then be calculated by simple difference as (PENWEIGHT ${ }_{\mathrm{DM}}-$ PENWEIGHT $_{\mathrm{SAND}}$ ).

\section{Whole-Pen Determinations of Nutrient Digestibility}

The described techniques for estimating PENWEIGHT $_{\text {EXCRETA }}$ from each research pen also allows for the estimation of DM, OM, and NDF digestibility on a whole-pen basis. Normally, total-tract apparent digestibilities of DM or other nutrients within 
individual animals are assessed with a staggered approach to diet, ort, and fecal collections to account for the lag time between diet consumption and production of feces (Cochran and Galyean, 1994). Our whole-pen protocol was adapted to comply with the routine production-management procedures within the research barn. As such, the sampling of the diet and associated nutrient intakes were not based on independent samples and measurements obtained specifically during the 2 to $3 \mathrm{~d}$ immediately preceding or during excreta collection. Rather, these were based on the mean weekly DMI recorded for each pen. Subsequently, intakes of $\mathrm{OM}$ and NDF were calculated as the product of the mean weekly DMI for each pen and the associated concentration of OM or NDF for each diet determined as part of the routine weekly analysis of diets. For this application, both sulfite and heat-stable amylase were included within the NDF solution (Goering and Van Soest, 1970; Mertens, 1992). Concentrations of OM and NDF were determined similarly on dried $\left(55^{\circ} \mathrm{C}\right)$, ground $(1-\mathrm{mm}$ screen $)$ subsamples of the composite fecal samples collected directly from each heifer within each pen, and gross indigestible OM or NDF output from each pen was calculated as the product of this OM or NDF concentra-

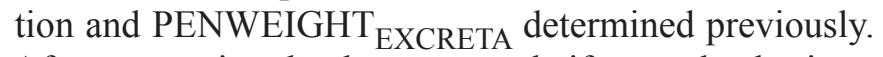
After converting the data to a per heifer per day basis, a whole-pen estimate of apparent nutrient (OM or NDF) digestibility was calculated as $100 \%-$ [(indigestible nutrient output/nutrient intake) $\times 100 \%$ ]. For estimates of NDF digestibility, there was visual evidence that heifers ingested sand from the freestalls during their routine daily activities. Sand is recovered as ash within the feces and can potentially depress NDF digestibility. For this reason, NDF digestibility was quantified based on inputs determined with and without correction for residual ash.

\section{Verification of Nutrient Digestibilities with an Internal Marker}

Nutrient digestibility estimates obtained from whole-pen collections were verified by analyzing diet and fecal samples for concentrations of indigestible NDF (Cochran et al., 1986). Indigestible NDF was quantified with a 144-h incubation in buffered rumen fluid (Daisy II Incubator; ANKOM Technology Corp., Macedon, NY) followed by a terminal digestion in neutral-detergent solution that contained both sodium sulfite and heat-stable $\alpha$-amylase (ANKOM200 Fiber Analyzer; ANKOM Technology Corp.). Rumen fluid was harvested from 2 nonlactating donor cows consuming an alfalfa-grass, haylage-based diet (15.9\% CP, 47.1\% NDF, 36.5\% ADF, and $61.5 \%$ TDN; University of Wisconsin Soil and Forage Laboratory, Marshfield, WI). Concentrations of indigestible NDF were determined with and without re- sidual ash based on combustion of fiber residues for 6 $\mathrm{h}$ at $500^{\circ} \mathrm{C}$. Apparent digestibilities of DM were then calculated as $100 \%-[100 \% \times(\%$ marker in diet $) /(\%$ marker in feces)] (Cochran and Galyean, 1994).

\section{Statistics}

Data were analyzed using PROC MIXED (SAS Inst. Inc., Cary, NC) as a randomized complete block design based on the model defined by St-Pierre (2007) for replicated pen studies. For this application, block (heifer-BW group) was considered to be a fixed effect. Treatment means were evaluated by 4 orthogonal contrasts that included 1) all ad libitum diets (EGG0, EGG9, EGG18, and EGG27) vs. LF, 2) EGG0 vs. all diets containing EGG (EGG9, EGG18, and EGG 27), 3) linear effect of serial addition of EGG, and 4) quadratic effect of serial addition of EGG.

\section{RESULTS AND DISCUSSION}

\section{Input Weights and Concentrations}

Measured inputs required to estimate PENWEIGHT $_{\text {EXCRETA }}$ are summarized in Table 1. The weight of sand collected from each pen (PENWEIGHTSAND) ranged from 241 to $430 \mathrm{~kg}$ (data not shown) and comprised about $85 \%$ of the total DM obtained from each pen after the 48-h collection period. The large proportion of sand in the total collection from each pen is likely explained by the deep sand bedding within the stalls and a generally greater activity level for heifers relative to that observed commonly for lactating cows. Masses of PENWEIGHT ${ }_{\mathrm{WET}}$, PENWEIGHT $_{\mathrm{DM}}$, PENWEIGHT $_{\mathrm{ASH}}$, and PENWEIGHT SAND $_{\text {(data not }}$ shown) were highly variable across collection periods, produced large SEM, and did not vary $(P \geq 0.47)$ on the basis of dietary treatment. Similarly, no significant contrasts were detected across dietary treatments for $\mathrm{CONCPEN}_{\mathrm{DM}}$ (overall mean $=43.6 \% ; P \geq 0.22$ ) or $\mathrm{CONCPEN}_{\mathrm{ASH}}$ (overall mean $=81.7 \% ; P \geq 0.33$ ). Fecal samples collected directly from each heifer and composited within each collection pen exhibited greater CONCFECAL ${ }_{\mathrm{ASH}}$ from LF heifers compared with those offered diets for ad libitum intake (18.8 vs. 15.1\%; $P=0.001)$, and there was a quadratic effect $(P=0.013)$ associated with inclusion rate of EGG within ad libitum diets.

After the contributions from sand bedding to the gross whole-pen collections were removed mathematically using concentrations of ash as an internal marker,

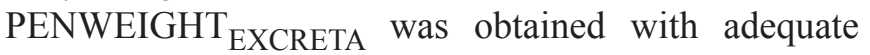
sensitivity to detect differences between LF and all ad libitum diets (54 vs. $62 \mathrm{~kg} ; P=0.003$ ). Likewise, the 
Table 1. Whole-pen collection characteristics for heifers consuming diets with serial additions of eastern gamagrass (EGG) or a limit-fed (LF) control alfalfa/corn silage diet at Marshfield, WI; all pen collection weights represent $48 \mathrm{~h}$ of collection from pens containing 8 dairy heifers

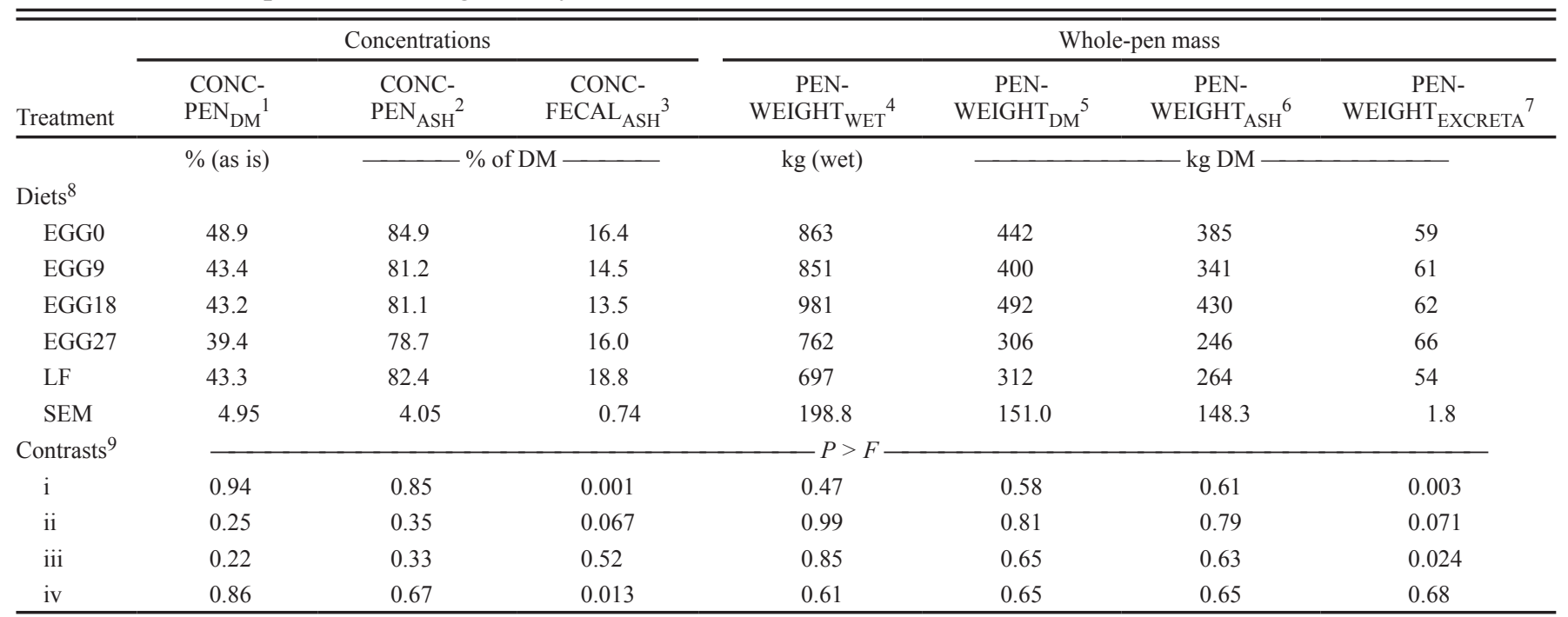

${ }^{1} \mathrm{CONCPEN}_{\mathrm{DM}}=$ concentration of DM within whole-pen contents (\%, as is basis).

${ }^{2} \mathrm{CONCPEN}_{\mathrm{ASH}}=$ concentration of ash within whole-pen contents ( $\%$ of DM).

${ }^{3} \mathrm{CONCFECAL}_{\mathrm{ASH}}=$ concentration of ash obtained directly from heifers by rectal palpation ( $\%$ of DM).

${ }^{4}$ PENWEIGHT ${ }_{\mathrm{WET}}=$ gross wet weight $(\mathrm{kg})$ of pen contents collected after $48 \mathrm{~h}(\mathrm{~kg})$.

${ }^{5}$ PENWEIGHT $_{\mathrm{DM}}=$ gross weight of DM collected from each pen after $48 \mathrm{~h}(\mathrm{~kg})$.

${ }^{6} \mathrm{PENWEIGHT}_{\mathrm{ASH}}=$ gross weight of ash collected from each pen after $48 \mathrm{~h}(\mathrm{~kg})$.

${ }^{7}$ PENWEIGHT EXCRETA $=$ gross weight of excreta DM collected from each pen after $48 \mathrm{~h}(\mathrm{~kg})$.

${ }^{8} \mathrm{EGG} 0$ = alfalfa haylage/corn silage diet containing no EGG offered for ad libitum intake; EGG9 = alfalfa haylage/corn silage diet containing $9.1 \%$ EGG offered for ad libitum intake; EGG18 = alfalfa haylage/corn silage diet containing 18.3\% EGG offered for ad libitum intake; EGG27 = alfalfa haylage/corn silage diet containing 27.4\% EGG offered for ad libitum intake; and LF = EGG0 diet offered at 85\% of intake for EGG0.

$9_{\mathrm{i}}=$ all ad libitum diets (EGG0, EGG9, EGG18, and EGG27) vs. LF; ii = EGG0 vs. all diets containing EGG (EGG9, EGG18, and EGG 27); iii = linear effect of serial addition of EGG; iv = quadratic effect of serial addition of EGG.

technique detected a tendency for EGG0 to differ from all ad libitum diets containing EGG (59 vs. $63 \mathrm{~kg} ; P=$ $0.071)$ and an expected linear $(P=0.024)$ increase in PENWEIGHT $_{\text {EXCRETA }}$ concomitant with increasing proportions of EGG in the treatment diets. After conversion to a per heifer/day basis (Table 2), the technique yielded a pooled SEM for DM excretion across all dietary treatments of $0.113 \mathrm{~kg} \cdot$ heifer $^{-1} \cdot \mathrm{d}^{-1}$, which is a considerably more sensitive measurement than reported for previous whole-pen evaluations (Hoffman et al., 2007; Kruse et al., 2010; Bjelland et al., 2011). However, the $13 \%$ reduction in DM excretion observed for heifers offered the LF diet relative to those offered ad libitum diets was consistent with responses reported in other studies (Hoffman et al., 2007; Kruse et al., 2010). Generally, our responses to treatment for OM excretion (Table 2) were similar to those observed for the excretion of $\mathrm{DM}$; OM excretion increased linearly $(P=0.010)$ with the proportion of EGG within the diet, and there were reductions $(2.72$ vs. $3.28 \mathrm{~kg} /$ day; $P<0.001)$ in these excretions for LF heifers relative to all other dietary treatments and for EGG0 compared with all diets containing EGG (3.06 vs. $3.35 \mathrm{~kg} /$ day; $P=0.015)$.

\section{Digestibility of Diets}

Dry Matter and OM. The whole-pen technique detected differences in apparent digestibility of DM for heifers consuming the EGG0 diet relative to diets containing any level of EGG (61.9 vs. $57.6 \% ; P=0.048)$ as well as a linear $(P=0.027)$ decrease in apparent DM digestibility that was inversely related to the percentage of EGG in the diet (Table 2). Overall, a differential of 6.0 percentage units (61.9 vs. 55.9\%) of apparent DM digestibility was observed between the EGG0 and EGG27 diets. Apparent digestibility estimates for OM generally described differences across dietary treatments that were similar to those for DM; OM digestibility was greater for the EGG0 diet compared with all diets containing EGG (65.7 vs. $60.8 \% ; P=0.023)$ and declined linearly $(P=$ 0.020 ) with the inclusion level of EGG within the diet.

Neutral Detergent Fiber. Estimates of apparent OM digestibility were numerically greater across all dietary treatments (overall mean $=62.5 \%$ ) than observed for corresponding estimates of apparent DM digestibility (overall mean $=58.8 \%$ ); this overall differential $(3.7$ percentage units) suggests that apparent DM digestibil- 
Table 2. Intakes, fecal excretions, and apparent digestibilities of DM and OM determined from whole pen collections of manure. Intakes and excretions are expressed on a per heifer basis

\begin{tabular}{|c|c|c|c|c|c|c|}
\hline Treatment & DMI & $\begin{array}{c}\text { DM } \\
\text { excretion }\end{array}$ & $\begin{array}{c}\text { DM } \\
\text { digestibility }\end{array}$ & $\begin{array}{c}\mathrm{OM} \\
\text { intake }\end{array}$ & $\begin{array}{c}\mathrm{OM} \\
\text { excretion }\end{array}$ & $\begin{array}{c}\text { OM } \\
\text { digestibility }\end{array}$ \\
\hline & $\mathrm{kg} / \mathrm{d}$ & $\mathrm{kg} / \mathrm{d}$ & $\%$ & $\mathrm{~kg} / \mathrm{d}$ & $\mathrm{kg} / \mathrm{d}$ & $\%$ \\
\hline \multicolumn{7}{|l|}{ Diets $^{1}$} \\
\hline EGG0 & 9.67 & 3.67 & 61.9 & 8.95 & 3.06 & 65.7 \\
\hline EGG9 & 9.35 & 3.84 & 59.0 & 8.64 & 3.27 & 62.2 \\
\hline EGG18 & 9.13 & 3.84 & 57.8 & 8.43 & 3.32 & 60.5 \\
\hline EGG27 & 9.33 & 4.11 & 55.9 & 8.61 & 3.45 & 59.7 \\
\hline LF & 8.33 & 3.37 & 59.4 & 7.71 & 2.72 & 64.5 \\
\hline SEM & 0.476 & 0.113 & 1.68 & 0.443 & 0.085 & 1.56 \\
\hline \multicolumn{7}{|l|}{ Contrasts $^{2}$} \\
\hline $\mathrm{i}$ & 0.079 & 0.003 & 0.70 & 0.085 & $<0.001$ & 0.18 \\
\hline ii & 0.48 & 0.071 & 0.048 & 0.46 & 0.015 & 0.023 \\
\hline iii & 0.58 & 0.024 & 0.027 & 0.55 & 0.010 & 0.020 \\
\hline iv & 0.59 & 0.67 & 0.78 & 0.60 & 0.61 & 0.40 \\
\hline
\end{tabular}

${ }^{1} \mathrm{EGG} 0=$ alfalfa haylage/corn silage diet containing no EGG offered for ad libitum intake; EGG9 = alfalfa haylage/corn silage diet containing 9.1\% EGG offered for ad libitum intake; EGG18 = alfalfa haylage/corn silage diet containing $18.3 \%$ EGG offered for ad libitum intake; EGG27 = alfalfa haylage/corn silage diet containing 27.4\% EGG offered for ad libitum intake; and $\mathrm{LF}=\mathrm{EGG} 0$ diet offered at $85 \%$ of intake for EGG0.

$2_{\mathrm{i}}=$ all ad libitum diets (EGG0, EGG9, EGG18, and EGG27) vs. LF; ii = EGG0 vs. all diets containing EGG (EGG9, EGG18, and EGG 27); iii = linear effect of serial addition of EGG; iv = quadratic effect of serial addition of EGG.

ity was suppressed slightly by recovery of nondietary ash within fecal samples. Without correction for nondietary ash, digestibility of NDF (Table 3 ) tended to be greater for ad libitum diets compared with the LF diet (40.5 vs. $33.6 \% ; P=0.061$ ), but no other contrast specifically evaluating NDF digestibility of ad libitum diets approached significance $(P \geq 0.58)$. When diet and fecal samples analyzed for concentrations of NDF were corrected for residual ash, responses to dietary treatment were very similar to those observed without correction for residual ash. However, the removal of residual ash also had predictable effects on the magnitude of NDF intake and excretion, reducing both measurements on a kilogram/day basis relative to non-ash-corrected estimates. This was especially obvious with respect to daily excretion, where the overall mean without correction for residual ash $(2.39 \mathrm{~kg} /$ day $)$ was numerically greater than observed after correction for residual ash $(2.02 \mathrm{~kg}$ /day). The effects of ash correction on subsequent estimates of NDF digestibility were substantial although no significant contrasts among dietary treatments were detected $(P \geq 0.28)$. The overall mean for NDF digestibility determined with ash correction across all diets $(46.9 \%)$ exceeded that determined without ash correction (39.1\%) by 7.8 percentage units; moreover, our ash-corrected NDF digestibility assessments agreed closely with in vi- tro estimates of NDF digestibility for these diets (49.0 to $53.2 \%$ of NDF; Coblentz et al., 2012).

\section{Verification of Whole-Pen DM Digestibility Estimates with Selected Internal Markers}

Estimates of apparent DM digestibility derived from the 144-h indigestible NDF internal marker yielded significant contrasts of LF vs. all ad libitum diets $(P=0.005)$, EGG0 vs. all diets containing EGG $(P=0.024)$, and a linear $(P=0.013)$ effect of inclusion rate for EGG within the diet (data not shown). However, internal-markerderived estimates of apparent DM digestibility (overall mean across all diets $=71.0 \%$ ) were greater than determined from whole-pen collections (Table 2). Although the quantity of fecal excretions was not measured directly via whole-pen collections, our per heifer estimates of DM excretion (Table 2) would suggest that marker recoveries for 144 -h indigestible NDF were 135 to $164 \%$. Because whole-pen intakes were measured directly, more confidence can be placed in measurements of the internal markers consumed; this suggests that excessive recoveries were likely caused by intentional or inadvertent consumption of sand bedding by lounging heifers. This hypothesis was tested by correcting indigestible NDF for residual ash and then calculating apparent DM digestibility from these revised marker concentrations. Based on these ash-corrected revisions, apparent DM digestibilities for the EGG0, EGG9, EGG18, EGG27, and LF diets were $67.2,65.8,66.0,60.5$, and $68.0 \%(\mathrm{SEM}=1.36 \%)$, respectively, resulting in a detectable linear decrease $(P=$ 0.008 ) for apparent DM digestibility that could be associated with EGG inclusion rate within the diet. Recoveries of the 144-h ash-corrected indigestible NDF marker estimated as described previously ranged from 112 to $128 \%$ across diets (overall mean $=120 \%$ ).

\section{Comments on Whole-Pen Estimates of Excreta Output}

Based on the results of this and several other recent studies (Hoffman et al., 2007; Kruse et al., 2010; Bjelland et al., 2011), the concept of whole-pen estimates of excreta output appears viable. For the present study, the use of sand-bedded freestalls permitted use of ash as an internal marker to mathematically separate quantities of bedding and excreta within the gross recovery of pen manure. It is unclear whether other procedural adjustments, such as installing bedding mattresses, could further improve the sensitivity of the excreta output measurement. In theory, many nutrient concentrations in excreta, such as $\mathrm{P}$ or fiber components, can be determined directly or reasonably approximated from fecal samples and then multiplied by the gross excreta weight from each pen to determine specific nutrient excreta loads from a pen 
of heifers over a 48-h period. However, this approach also has clear limitations, such as the inability to prevent volatilization of N (Hoffman et al., 2007). Furthermore, sensitive determination of specific nutrient loads within the excreta, coupled with daily intake measurements, potentially permits calculation of apparent digestibility coefficients. These method refinements are important for researchers lacking facilities for digestibility evaluations within individual animals and offer the additional benefit of minimal intrusion into normal animal routines, thereby eliminating concerns about lethargic or compromised eating behaviors by animals confined within digestion crates or tie-stalls for extended experimental periods (Cochran and Galyean, 1994).

Under the conditions described for this experiment, there are 2 practical limitations of this technique: 1) adequate mixing of sand and excreta within manure samples collected from each pen and 2) the necessity of correcting whole-pen collection data for residual ash within diet and fecal samples. We found that mixing of sand and excreta from gross whole-pen collections was best facilitated by discharging pen contents through a beater-type manure spreader and then by further mixing with a skid-steer loader. Because all calculations are based on concentrations of ash, rigorous sampling after manure mixing is absolutely essential. Second, ingestion of sand by lounging heifers will depress whole-pen estimates of apparent digestibility because this sand is recovered within fecal samples. Therefore, digestibility coefficients should be calculated on an ash-corrected basis as apparent OM digestibility or on an ash-corrected basis for other nonvolatile forage components, such as NDF.

Under conditions framed by the experimental design of the parent study, pooled SEM for excreta output of DM, OM, NDF, and NDF (ash corrected) were 0.113, $0.085,0.093$, and $0.075 \mathrm{~kg} \cdot$ heifer $^{-1} \cdot \mathrm{d}^{-1}$, respectively. For DM excretion, this was about one-third of the pooled SEM reported for bedded-pack whole-pen collection protocols, in which excreta had to be separated quantitatively from organic bedding materials through more cumbersome analytical procedures (Hoffman et al., 2007; Kruse et al., 2010).

Previously, Titgemeyer (1997) surveyed 120 published reports from the Journal of Animal Science for measures of variation associated with digestion measurements. Based on this summary of variability associated specifically with measuring total-tract OM digestion, it was concluded that 4 and 3 individual animal replications within a typical Latin square design were required to detect differences of 5 and $10 \%$ units of OM digestibility, respectively, assuming mean separation was conducted by least significant difference without $F$-test protection. If data from the present study are reanalyzed by PROC GLM of SAS to generate a least
Table 3. Intakes, fecal excretions, and digestibilities of NDF with and without corrections for ash as determined from whole-pen collections of manure. Intakes and excretions are expressed on a per heifer basis

\begin{tabular}{|c|c|c|c|c|c|c|}
\hline \multirow[b]{2}{*}{ Treatment } & \multicolumn{3}{|c|}{ Without correction for ash } & \multicolumn{3}{|c|}{ Corrected for ash } \\
\hline & $\begin{array}{c}\text { NDF } \\
\text { intake }^{1}\end{array}$ & $\begin{array}{c}\text { NDF } \\
\text { excretion }\end{array}$ & $\begin{array}{c}\text { NDF } \\
\text { digestibility }\end{array}$ & $\begin{array}{c}\mathrm{NDF} \\
\text { intake }^{1}\end{array}$ & $\begin{array}{c}\text { NDF } \\
\text { excretion }\end{array}$ & $\begin{array}{l}\text { NDF digest- } \\
\text { ibility }\end{array}$ \\
\hline & $\mathrm{kg} / \mathrm{d}$ & $\mathrm{kg} / \mathrm{d}$ & $\%$ & $\mathrm{~kg} / \mathrm{d}$ & $\mathrm{kg} / \mathrm{d}$ & $\%$ \\
\hline \multicolumn{7}{|l|}{ Diets $^{2}$} \\
\hline EGG0 & 3.80 & 2.31 & 39.3 & 3.64 & 1.91 & 47.5 \\
\hline EGG9 & 3.97 & 2.39 & 39.8 & 3.87 & 2.06 & 46.6 \\
\hline EGG18 & 4.13 & 2.42 & 41.5 & 4.02 & 2.13 & 47.1 \\
\hline EGG27 & 4.54 & 2.67 & 41.4 & 4.40 & 2.24 & 48.7 \\
\hline LF & 3.28 & 2.18 & 33.6 & 3.13 & 1.74 & 44.4 \\
\hline SEM & 0.086 & 0.093 & 2.95 & 0.072 & 0.075 & 2.38 \\
\hline \multicolumn{7}{|l|}{ Contrasts $^{3}$} \\
\hline i & $<0.001$ & 0.028 & 0.061 & $<0.001$ & 0.002 & 0.28 \\
\hline ii & 0.002 & 0.13 & 0.64 & $<0.001$ & 0.023 & 0.99 \\
\hline iii & $<0.001$ & 0.027 & 0.58 & $<0.001$ & 0.010 & 0.72 \\
\hline iv & 0.19 & 0.39 & 0.91 & 0.32 & 0.84 & 0.61 \\
\hline
\end{tabular}

${ }^{1}$ Intake of NDF based on NDF concentration of the diet determined with heat-stable amylase and sodium sulfite in the NDF solution; similarly, fecal output of NDF is based on concentrations of NDF in feces determined with the same additions to the NDF solutions as described for diet samples.

${ }^{2} \mathrm{EGG} 0$ = alfalfa haylage/corn silage diet containing no EGG offered for ad libitum intake; EGG9 = alfalfa haylage/corn silage diet containing $9.1 \%$ EGG offered for ad libitum intake; EGG18 = alfalfa haylage/corn silage diet containing 18.3\% EGG offered for ad libitum intake; EGG27 = alfalfa haylage/corn silage diet containing 27.4\% EGG offered for ad libitum intake; and $\mathrm{LF}=\mathrm{EGG0}$ diet offered at $85 \%$ of intake for EGG0.

$3_{\mathrm{i}}=$ all ad libitum diets (EGG0, EGG9, EGG18, and EGG27) vs. LF; ii = EGG0 vs. all diets containing EGG (EGG9, EGG18, and EGG 27); iii = linear effect of serial addition of EGG; iv = quadratic effect of serial addition of EGG.

significant difference for the apparent digestion of DM and $\mathrm{OM}$, the methods used in this project would detect differences of 5.0 and $4.9 \%$ units at the $P=0.05$ level of confidence, respectively. For apparent OM digestion, this level of sensitivity is comparable with that suggested for a typical $4 \times 4$ Latin square assessment conducted with individual animal replicates (Titgemeyer, 1997). Potentially, statistical power could be improved further through a variety of options; however, adding additional collections over a typical production trial lasting from 90 to $150 \mathrm{~d}$ would not be prohibitive on the basis of labor requirements or analytical costs. Generally, our whole-pen fecal collection system appears to be viable. The method is dependent on quantifying ash within feedstuffs, fecal samples, and whole-pen collections of excreta. Although acknowledging obvious limitations, such as potential for volatilization of some nutrients, the method seems especially suited for production-scale research facilities with limited laboratory analytical capacity. Apparent digestibility coefficients generated by this analytical approach should be based on OM because of intentional or inadvertent ingestion of sand by lounging heifers that can elevate ash concentrations within fecal 
samples, thereby depressing estimates of apparent DM digestibility. From a procedural perspective, improved techniques for mixing large volumes of pen manure or eliminating more sand from the housing system are worthy of future evaluation.

\section{LITERATURE CITED}

Bjelland, D. W., K. A. Weigel, P. C. Hoffman, N. M. Esser, and W. K. Coblentz. 2011. The effect of feeding dairy heifers diets with and without supplemental phosphorus on growth, reproductive efficiency, health, and lactation performance. J. Dairy Sci. 94:6233-6242.

Coblentz, W. K., P. C. Hoffman, N. M. Esser, and M. G. Bertram. 2012. Using eastern gamagrass to construct diets that limit intake and caloric density for dairy replacement heifers. J. Dairy Sci. 95:6057-6071.

Cochran, R. C., D. C. Adams, J. D. Wallace, and M. L. Galyean. 1986. Predicting digestibility of different diets with internal markers: Evaluation of four potential markers. J. Anim. Sci. 63:1476-1483.
Cochran, R. C., and M. L. Galyean. 1994. Measurement of in vivo forage digestion by ruminants. In: G. C. Fahey, editor Forage quality, evaluation, and utilization. Nat. Conf. on Forage Quality, Evaluation, and Utilization. Univ. of Nebraska, Lincoln. 1315 Apr. 1994. ASA, CSSA, SSSA, Madison, WI. p. 613-643.

Goering, H. K., and P. J. Van Soest. 1970. Forage fiber analyses (Apparatus, reagents, procedures, and some applications). Agric. Handbook No. 379. USDA-ARS, Washington, DC. p. 8-11.

Hoffman, P. C., C. R. Simson, and M. Wattiaux. 2007. Limit feeding of gravid Holstein heifers: Effect on growth, manure nutrient excretion, and subsequent early lactation performance. J. Dairy Sci. 90:946-954.

Kruse, K. A., D. K. Combs, N. M. Esser, W. K. Coblentz, and P. C. Hoffman. 2010. Evaluation of potential carryover effects associated with limit feeding gravid Holstein heifers. J. Dairy Sci. 93:5374-5384.

Mertens, D. R. 1992. Critical conditions in determining detergent fibers. In: Proc. Natl. Forage Testing Assoc. Forage Anal. Workshop, Denver, CO. Natl. Forage Testing Assoc., Omaha, NE. p. C-1.

NRC. 2001. Nutrient requirements of dairy cattle. 7th rev. ed. National Academy Press, Washington, DC.

St-Pierre, N. R. 2007. Design and analysis of pen studies in the animal sciences. J. Dairy Sci. 90(E. Suppl.):E87-E99.

Titgemeyer, E. C. 1997. Design and interpretation of nutrient digestion studies. J. Anim. Sci. 75:2235-2247. 